\title{
Flight Test Limitations and Strategic Arms Control
}

\author{
Miroslav Nincic* \\ Department of Political Science, University of Michigan
}

\section{The relentless drive of military technology}

The current revival of the cold war and the associated surge in the superpower arms race have sparked a widespread and articulated concern on matters ranging from the economic consequences of uncontrolled military growth to the danger of nuclear confrontation. It is well to realize, however, that the record of arms control has been rather lamentable even when political relations were less bellicose. For each modest step toward military restraint, the arms race has taken several qualitative and quantitative bounds. This is partially, though certainly not exclusively, a consequence of the inability to control the relentless drive of military technology or to resist deployment of that which this technology produces. The search for arms limitation founders, in addition, on the lack of mutually acceptable criteria for comparing, and hence balancing, the ceilings to be imposed on both sides' arsenals. ${ }^{1}$

Nevertheless, even three decades is insufficiently long to cause total despair and the quest for improved paths to arms control must display a new dose of vigor. One proposal which merits careful examination concerns a ban, or a very restrictive quota, on the testing of major weapon systems. ${ }^{2}$ While this can be broadly interpreted, my focus will be on strategic missiles.

* Dr. Miroslav Nincic is Assistant Professor at the Department of Political Science and the Institute of Public Policy Studies at the University of Michigan, USA.

\section{Curbs on the rate of technological in- novation}

A negotiated and sufficiently low limit on the number of test firings of such missiles could impose practical curbs on the rate of technological innovation in the strategic realm (though it could not freeze it altogether) by inhibiting an important method of validating new designs and of assessing incremental improvements to existing systems. Thus, by hobbling the process of military growth at an early stage, the pace of the arms race could be controlled even in the absence of explicit agreements on numerical ceilings for deployed weapons.

Technological momentum has not only expanded the size of weapons inventories but, by increasing the accuracy and reliability of missiles, it has encouraged misguided notions of limited nuclear warfare and has exacerbated crisis instability by endowing the concept of preemptive counterforce strikes with a modicum of plausibility. Sufficiently restrictive limits on flight tests could, however, decrease each side's confidence in the reliability of its nuclear arsenal and hence decrease the expectation of first strikes. Doubts about levels of precision could, furthermore, dampen the appeal of 'limited' nuclear exchanges. Thus, not only would arms limitation benefit, but the likelihood of warfare might be significantly reduced.

\section{Limitations on flight testing}

Unlike NASA, the military in the United States does rely extensively on flight tests at several 
stages in the development of strategic missilery, notably: (1) Research \& Development (R\&D) testing of the full system, (2) operational flights for early production models, and, (3) post-deployment tests for continued operational effectiveness. Although some of the same data can be obtained through simulations and by the static firing of rocket motors, even the results of surrogate modes of evaluation should, ideally, be validated by actual operational test flights of the entire system. Moreover, these supplementary methods of evaluation appear less well suited to assessing the effects of possible storage-induced deterioration of components. (Titan ICBMs, for example, have not been tested in over six years and confidence in their reliability is correspondingly fragile.)

Which strategic weapons would be affected by an agreement of this sort? This would partly depend on the timing of such an agreement since many of the strategic systems under current development have been subjected to at least some preliminary testing and an accord would have to take virtually immediate effect to threaten their deployment. Flight tests on the new MX system are scheduled to begin in early 1983 and to span approximately three years. Clearly, the fate of this system would be unaffected by an agreement that took several years to negotiate. Flight tests on the Trident II SLBM and on the Soviet SS-N-20 submarine launched missile have already begun and the introduction of these missiles could only be thwarted by an immediate test ban.

However, even a limitation on flight testing negotiated in say three to five years could spare both superpowers certain forms of strategic weaponry. Ballistic missile defense systems, for example, could be discouraged: a desirable outcome since these could provide further encouragement to those who believe that a nuclear war might not be an entirely devastating affair. If an adequate interceptor missile were to function within the atmosphere (the principle of endo-atmospheric defense), it may have to be based on ramjet rather than turbojet propulsion - a technology that could require several more years for development. Even interceptors designed for missions outside the atmosphere would call for a wholly new (and rather large) missile. A ban, or very restrictive quota, on ramjet testing could also preclude the eventual development of missiles built to fly on depressed trajectories - a development that would further reduce each side's warning time and incite a reliance on dangerous 'launch on warning' strategies.

\section{Deterrence not affected}

The effects of test limitations of the sort discussed here carry over into the post-deployment phase of new weaponry. Virtually all missiles must undergo proof-testing to check for various forms of time-induced and storageinduced deterioration. While this can be partly established by surrogate forms of testing, actual flight tests of a statistically significant sample of the deployed system must also be performed to acquire an adequate estimate of the arsenal's reliability. ${ }^{3}$ Were this not possible, confidence in the missile's ability to perform its mission may diminish. This would not affect the real or perceived ability to strike retaliatory countervalue blows and deterrence should remain unaffected. But the ability to undertake far more exacting counterforce operations would come to be seriously questioned, the temptation to launch disabling firststrikes in crisis situations would decrease, and the danger of nuclear warfare would be mitigated.

Reference to flight test restriction is not entirely absent from arms control discussions. Indeed, both the Kennedy-Hatfield and the Gore proposals make incidental allusion to such restrictions. Still, more than this is needed and an explicit and comprehensive program designed to accomplish such limitations should be designed - as a complement, rather than a supplement, to other strategies.

An additional appeal of this approach is that the issue of verifiability should not be very contentious. Test firings of strategic missiles are continuously and adequately monitored via 'national technical means', i.e., satellite photography and radar, and any violation of an 
Igreement could easily be detected. In addiion, the apparently decreasing Soviet aversion o the idea of on-site inspections might remove :ven the most remote chance of clandestine ton-compliance.

\section{NOTES}

1. These and other problems are discussed in Miroslav Nincic, The Arms Race: The Political Economy of Military Growth (New York: Praeger, 1982).

2. An early statement of the need for such an approach is presented in Sidney Drell, 'Beyond SALT II: A Missile Test Quota',Bulletin of the Atomic Scientists, May 1977, pp. 3442.

3 . This is extensively discussed in Farooq Hussain, 'The Impact of Weapons Test Restrictions', Adelphi Papers, International Institute for Strategic Studies, London 1981. 